\title{
A NEW METHOD BASED ON ARTIFICIAL BEE COLONY ALGORITHM FOR THE OPTIMAL LOCATION OF SHUNT CONNECTED FACTS DEVICES
}

\author{
Kadir Abacı ${ }^{a}$, Volkan Yamaçlı ${ }^{b^{*}}$ \\ ${ }^{a}$ Department of Electrical and Electronics, Faculty of Engineering, \\ Mersin University, Mersin, Turkey \\ kabaci@mersin.edu.tr \\ $b^{*}$ Department of Electrical and Electronics Engineering, Faculty of Engineering, \\ Mersin University, Mersin, Turkey (corresponding author) \\ vyamacli@mersin.edu.tr
}

\begin{abstract}
In this paper, a new and easy to implement heuristic method related to the Artificial Bee Colony (ABC) algorithm is proposed for the optimal location of shunt connected Flexible AC transmission systems (FACTS) devices such as Static Var Compensator (SVC) and Static Synchronous Compensator (STATCOM) randomly and dynamically. Voltage stability enhancement, voltage profile improvement and active power loss minimization by using minimum number of devices and var compensator sizing are defined as the objective functions for the proposed methodology. Optimization results of the bi-objective and multi-objective functions are compared with the results reported in literature. Also, by comparing the results obtained by using $\mathrm{ABC}$ algorithm and Differential Evolution (DE) method, it can be stated that proposed algorithm can converge to better results by using minimum device number.
\end{abstract}

Keywords: Artificial bee colony, power systems, statcom, svc, voltage stability, optimization

\section{Introduction}

Traditionally, shunt capacitors are used as reactive power compensators in electrical networks. The main benefits of their utilization are achieving the minimal power loss amount, improvement of total voltage profile for the available load buses, and increasing the maximum transmitted power networks. Providing sufficient reactive power to the necessary 
load buses not only reduces the active power loss but also improves the voltage profile, and overcomes the instability issues on the system voltage. Hence, in recent best and optimal utilization of power system capabilities by including FACTS devices is a popular topic in power engineering.

Amongst the reactive power compensation devices, FACTS devices which can be connected in shunt have an indispensable and important task in supplying the necessary amount of reactive power to the electrical network as needed in order to improve the stability of system voltage level. SVC is a widely used FACTS device that is generally used in transmission networks due to low cost and good performance with the purpose of improving the voltage stability. There is another compensator device, STATCOM, which is also connected to load buses in shunt. This device, like SVC, is also an important member of the FACTS family which are started to be used especially in long range transmission lines. The sole shunt capacitor, SVC and STATCOM improves the security and quality of power by increasing the margin of system voltage stability and capacity of both active and reactive power transfer [14]. There are also other FACTS devices such as UPFC and SSSC regarding to improve the voltage stability in literature $[5,6]$.

The advantage of reactive power compensation mainly depends on the optimal size and placement of the compensator devices. Locating these controllers in shunt for all necessary load buses is nearly impossible and also unnecessary due to heavy economical issues. Thus, achieving the optimal number, capacity and the location of shunt var compensator can maximize the voltage profile improvement while maintaining requested high-quality operating conditions. There are different techniques which are used to optimize the FACTS placement in literature such as Lagrange multiplier techniques (LM) [7], the decompositioncoordination method (DCM) [8], genetic algorithm (GA) [9], artificial bee algorithm [10], particle swarm optimization (PSO) and non-dominated sorting particle swarm optimization (NSPSO) [11,12], simulated annealing (SA) [13], harmony search (HS) and improved harmony search (IHS) [14,15]. Lagrange multiplier techniques and simulated annealing algorithm used for optimal SVC planning and voltage stability enhancement in [7]. Genetic algorithm was used to improve the loadability of the system by using four different devices (TSCS, TCVR, TCPST, SVC) in [9]. In [10], the fuel cost along the loadability of the system is improved significantly by using SVC devices for the appropriate load buses. There are also some papers regarding the voltage profile improvement and reducing power loss which use particle swarm optimization and genetic algorithm [11]. In [12] it is presented that SVC and TCSC devices are used with aim to optimize a multi objective voltage stability problem. There is also an algorithm based on the SA is used to fix the location and type of shunt Var sources and their settings for various conditions with aim to improve security [13]. It is also presented the locating the FACTS devices optimally in order to improve security of the power systems [14]. Optimal allocation and sizing of SVC devices are applied to a transmission system in by using IHS [15].

This paper investigates $\mathrm{ABC}$ algorithm which uses foraging behaviour of honey bees for finding the best food source. The $\mathrm{ABC}$ algorithm is a newly developed optimization algorithm in order to overcome the non linear mathematical problems and can be used for power engineering problems such as placing and sizing the FACTS devices in optimal settings with the purpose of decreasing the real power loss (PL), enhancing the voltage profile (VD) and the voltage stability. In this work, a new optimal location method based on the ABC algorithm is proposed. The proposed method can achieve the optimal results for bi-objective and multiobjective problems by deciding the best type and location of the compensator. 


\section{Facts modeling}

As aforementioned above, this work focuses on the optimal settings and location of two types of shunt FACTS devices, SVC and STATCOM. Modeling of these devices used in this study is given in detail below.

\subsection{SVC model}

The SVC susceptance model which represents the reactive power input at the load buses [16] is implemented and used in this paper as shown in Figure 1. The output of this FACTS device is modeled to switch between capacitive or inductive load in order to maintain the stability of the electrical power system.

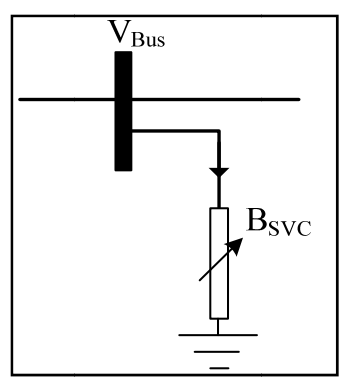

Figure 1. Susceptance model of SVC

Figure 2 shows the V-I characteristics of SVC, which has a capacitive limit and an inductive limit. At the capacitive limit SVC becomes a shunt capacitor and at the inductive limit the SVC becomes a shunt reactor .

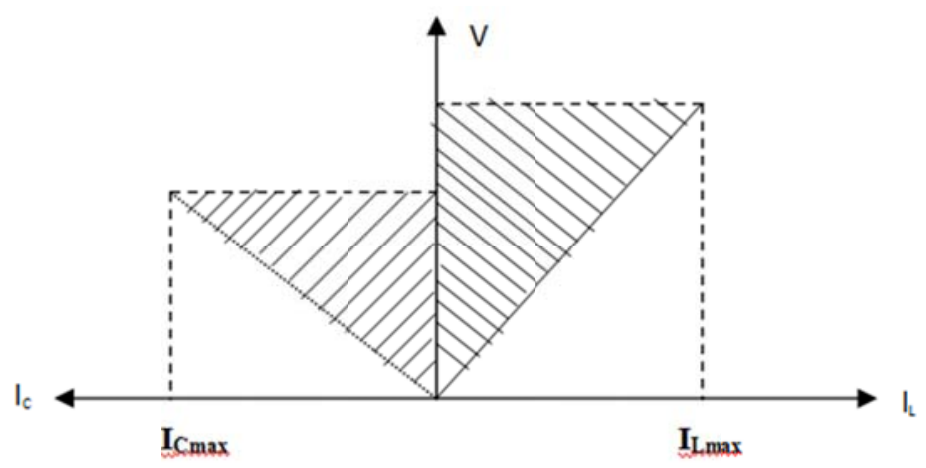

Figure 2. V-I characteristictics of SVC[1]

The reactive power amount injected by the SVC (Qsvc) for the bus $\mathrm{k}(\mathrm{Qk})$ can be written as,

$Q_{S V C}=Q_{k}=-V_{k}^{2} B_{S V C}$

where $\mathrm{V}_{\mathrm{k}}$ and $\mathrm{B}_{\mathrm{SVC}}$ represent the voltage and the equivalent susceptance value of SVC device at bus $\mathrm{k}$, respectively. 


\subsection{STATCOM model}

STATCOM is a similar device to SVC which can regulate the voltage profile of the load buses better compared to SVC. It consists of a DC capacitor and an inverter that can be connected to the line in parallel. The circuit modeling of the device is shown in Figure 3.

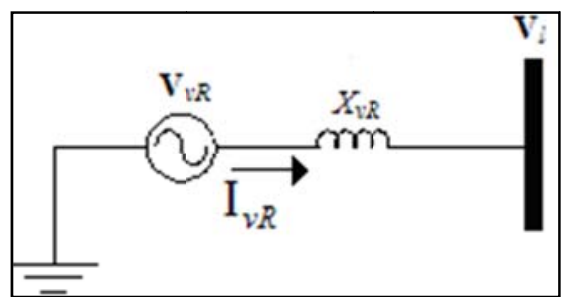

Figure 3. STATCOM equivalent circuit

The typical V-I characteristic of STATCOM is depicted in Figure 4.a) that STATCOM can supply both capacitive and inductive compensation and is able to control output current over the rated maximum capacitive and inductive range independently of the ac system voltage. It can be seen in the figure that maximum reactive power generation or absorption changes linearly with the ac system voltage.

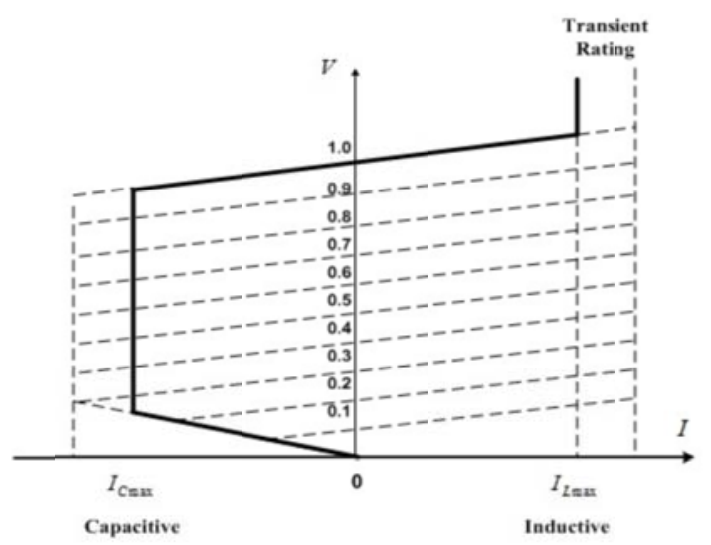

a)

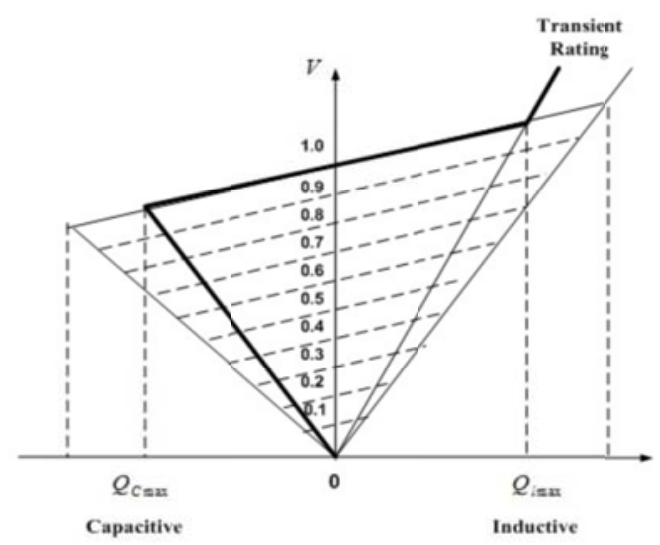

b)

Figure 4. a)Typical voltage and reactive power characteristics of STATCOM b) Typical voltage and reactive power characteristics of SVC [17]

Main load flow equation regarding to STATCOM can be presented as (2) and (3) [16], thus the expression for the shunt system shown in Figure 3 is given by:

$$
\begin{aligned}
& E_{v R}=V_{v R}\left(\cos \partial_{v R}+j \sin \partial_{v R}\right) \\
& S_{v R}=P_{v R}+j Q_{v R}=V_{v R} Y_{v R}\left(V_{v R}^{*}-V_{l}^{*}\right)
\end{aligned}
$$

where $V_{v R}$ and $Y_{v R}$ represents voltage source and the admittance of the STATCOM, respectively. 


\section{Optimal power flow}

In OPF problem considered in this study, the main objective is optimizing one or more objective functions while fulfilling some constraints such as load flow, generation bus voltages magnitudes, load bus voltage magnitude, shunt VAR compensator, reactive power generation, transformer taps setting etc.

The problem is formulated as,

Optimize: $f(x, u)$ with the subject of: $g(x, u)=0$ and $h(x, u) \leq 0$ in accordance with,

$x=\left[\begin{array}{llll}P_{\text {Slack }} V_{L} Q_{G} S_{l}\end{array}\right]$

$u=\left[\begin{array}{llll}P_{G} & V_{G} & Q_{C} & T\end{array}\right]$

In equation (3), $x$ represents state variables; real power of slack bus $\mathrm{P}_{\text {Slack, }}$, voltage of load bus $\mathrm{V}_{\mathrm{L}}$, reactive power generation $\mathrm{Q}_{\mathrm{G}}$ and line loading $\mathrm{S}_{\mathrm{l}}$. In equation (4), $u$ represents the variable vector for the elements including the real power $P_{G}$, generator voltage $V_{G}$, the output of shunt VAR compensators $\mathrm{Q}_{\mathrm{C}}$ and settings of the tap changing transformers $\mathrm{T}, \mathrm{f}$ and $\mathrm{g}$ indicate the objective function and load flow equations respectively while $h$ represents the parameter constraints.

\subsection{System constraints}

The typical equations related to load flow, $g(x, u)$, in the literature are given by,

$$
\begin{aligned}
& P_{G_{i}}-P_{D_{i}}-\sum_{j=1}^{n}\left|V_{i}\right|\left|V_{j}\right|\left|Y_{i j}\right| \cos \left(\theta_{i j}-\delta_{i}+\delta_{j}\right)+P_{\text {injFACTS }_{i}} \\
& Q_{G_{i}}-Q_{D_{i}}-\sum_{j=1}^{n}\left|V_{i}\right|\left|V_{j}\right|\left|Y_{i j}\right| \sin \left(\theta_{i j}-\delta_{i}+\delta_{j}\right)+Q_{\text {injFACTS }_{i}}
\end{aligned}
$$

where $\mathrm{P}_{\mathrm{Gi}}$ and $\mathrm{Q}_{\mathrm{Gi}}$ are the real and imaginary power outputs, $\mathrm{P}_{\mathrm{Di}}$ and $\mathrm{Q}_{\mathrm{Di}}$ are active load and reactive load demand at bus $i$. The elements of the bus admittance matrix magnitude and phase angle are represented by $\left|Y_{\mathrm{ij}}\right|$ and $\theta_{\mathrm{ij}}$, respectively. $\mathrm{P}_{\text {injFACTSi }}$ is injected active power and $\mathrm{Q}_{\text {injFACTSi }}$ is injected reactive power at bus $\mathrm{i}$.

Parameter constrains, $\mathrm{h}(\mathrm{x}, \mathrm{u})$ including the typical load flow constraints are given in (8) - (10) where $\mathrm{N}_{\mathrm{G}}$ defines number of generators,

$\begin{array}{ll}V_{G i}^{\min } \leq V_{G i} \leq V_{G i}^{\max } & i=1, \ldots \ldots, N_{G} \\ P_{G i}^{\min } \leq P_{G i} \leq P_{G i}^{\max } & i=1, \ldots \ldots, N_{G} \\ Q_{G i}^{\min } \leq Q_{G i} \leq Q_{G i}^{\max } & i=1, \ldots, N_{G}\end{array}$

Maximum and minimum limits of tap settings regarding the transformer and the reactive power constraints which can be injected or absorbed by compensators are given by (11) and (12) where $\mathrm{N}_{\mathrm{T}}$ and $\mathrm{N}_{\mathrm{QC}}$ define number of transformer and reactive compensators, respectively. 


$$
\begin{array}{ll}
T_{i}^{\min } \leq T_{i} \leq T_{i}^{\max } & i=1, \ldots \ldots, N_{T} \\
Q_{C i}^{\min } \leq Q_{C i} \leq Q_{C i}^{\max } & i=1, \ldots \ldots, N_{Q G}
\end{array}
$$

\subsection{Security constraints}

The load bus voltage constraints and the maximum value of loadability capacity of the transmission line are given by (13) and (14), respectively. $N_{V L}$ represents number load bus voltage variables while $\mathrm{N}_{\mathrm{SL}}$ represents the number transmission line loading variable.

$$
\begin{array}{ll}
V_{L i}^{\min } \leq V_{L i} \leq V_{L i}^{\max } & i=1, \ldots \ldots, N_{V L} \\
S_{L i} \leq S_{L i}^{\max } & i=1, \ldots \ldots, N_{S L}
\end{array}
$$

\section{Implementation of ABC Algorithm For Optimal Location}

Recently, the optimization methods based on the swarm intelligence attract a lot of interest in area of science and engineering in order to solve multi-dimensional and non-linear optimization problems. In the $\mathrm{ABC}$ algorithm; foraging behavior, location of food sources and nectar quality represent the problem, the possible solutions and quality of the solution, respectively. In ABC algorithm, the labor and worker bee characteristics are divided in three groups to employ the honey bees named as employed, onlooker and scout bees. These search patterns symbolizes the generation of initial food sources, exploiting and exhausting respectively.

Employed bees: Randomly search for food source positions (solutions) and then share the information that is nectar amounts by dancing with the bees waiting in the hive. Duration of dance depends on the nectar amount (fitness value) of the food source.

Onlooker bees: Watch dances of various employed bees and chose the good food source position according to quality of that food source.

Scout bees: An employed bee of the source which is abandoned becomes a scout and starts to search a new food source randomly.

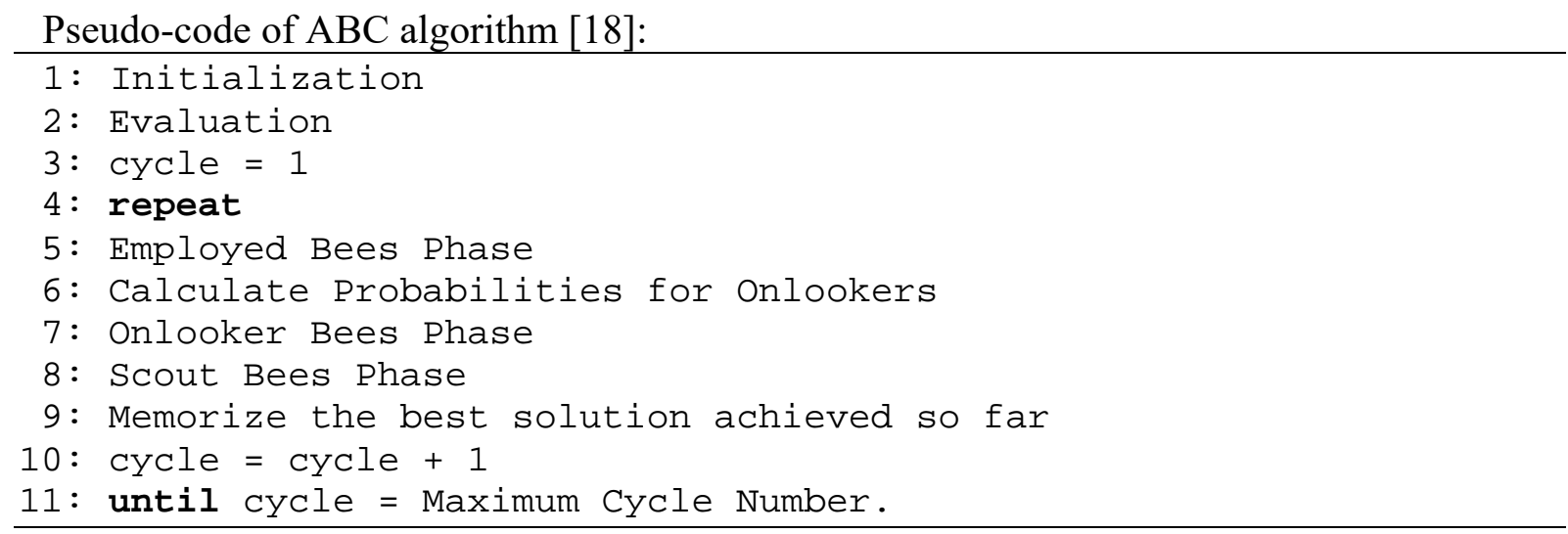

The procedure of the algorithm considered in this work is given below. 
Step 1. ABC parameters and mathematically modeled systems constraints such as real power generation, voltage magnitude and the location of shunt FACTS devices are defined.

Step 2. Randomly generated initial vector is achieved by using (15).

$P_{i j}=P_{j \min }+\operatorname{rand} \times\left(P_{j \max }-P_{j \min }\right)$

Step 3. Evaluate the objective function values and so the fitness values by using equation (16).

fitness $_{i}=\left\{\begin{array}{c}1 /\left(1+f_{i}\right), 0 \leq f_{i} \\ 1+\operatorname{abs}\left(f_{i}\right), 0>f_{i}\end{array}\right.$

Step 4. A new solution set vector is generated corresponding to (17). The objective function and fitness for newly generated solution sets are evaluated by using optimal power flow.

$P_{i j n e w}=P_{i j}+\emptyset \times\left(P_{i j}-P_{k j}\right) \quad(i \neq k, \emptyset=\operatorname{rand}[-1,1]$

Step 5. The probability function, which is unique for $\mathrm{ABC}$ algorithm, is achieved and evaluated by using (18) which leads evaluating the fitness value and select the best solution set for each food source. SN defines number of population chosen by the user.

$p_{i}=\frac{\text { fitness }_{i}}{\sum_{i=1}^{S N} \text { fitness }_{i}}$

Step 6. If the current solution set cannot be improved after trying up to the limit defined by user, that solution set is abandoned and a new one is created by jumping to Step 2 .

Step 7. The best solution set achieved this far is memorized. Function loop is stopped if the criterion is met, otherwise the algorithm jumps to Step 4 and continue iteration process. Flowchart of artificial bee colony algorithm is given by Figure 5 . 


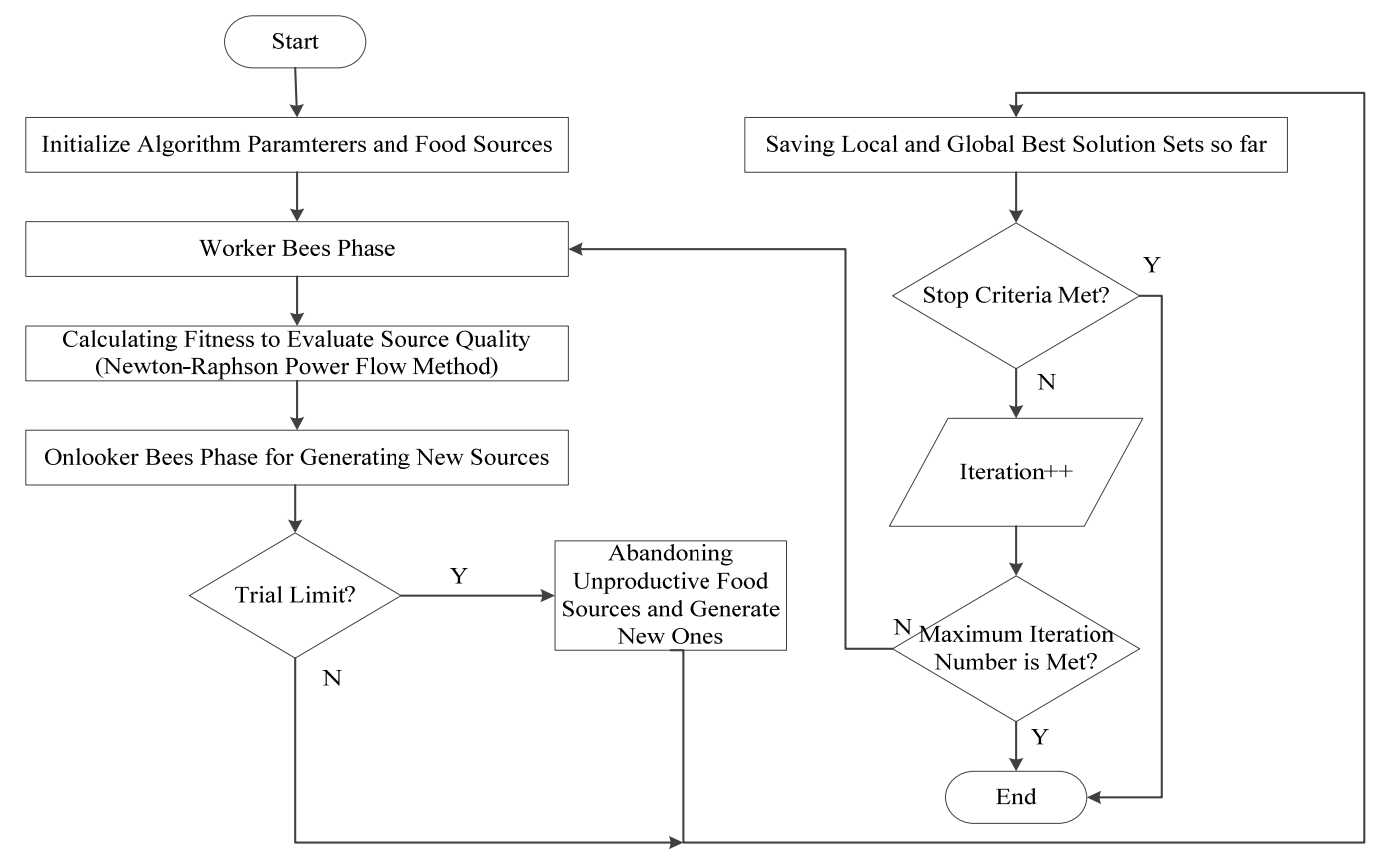

Figure 5. Flowchart of artificial bee colony algorithm implemented with optimal power flow

\section{Results and discussion}

The proposed method is applied to IEEE 30 bus [19] power system. Objective function of the system is considered to have only one objective by achieving the optimal placement of SVC and STATCOM devices at first. These devices are randomly located for the load buses. By satisfying the single objective purpose, the optimization problem is considered to be multi objective optimization problem by satisfying shunt device type, minimum number of devices and reactive power amount. The placement of these devices are decided randomly by the proposed algorithm and results are given by Table 1. Minimum power loss is obtained by placing 2 SVC on buses 15 and 20 respectively as the minimum voltage deviation is obtained by placing SVC and STATCOM on buses 19 and 24 respectively. In order to improve voltage stability, one SVC and one STATCOM devices are located on the buses 19 and 21.

\subsection{Case 1 - Power loss minimization}

The proposed algorithm also considers the transmission loss minimization by selecting optimal location of FACTS devices. The real power losses can be calculated using (19).

$f_{1}=\sum_{i=1}^{N_{L}} g_{l}\left[V_{k}^{2}+V_{m}^{2}-2 V_{k} V_{m} \cos \left(\delta_{k}-\delta_{m}\right)\right]$

where $\mathrm{g}_{\mathrm{i}}$ is the conductance of the $\mathrm{i}^{\text {th }}$ line; $\mathrm{V}_{\mathrm{k}}$ and $\mathrm{V}_{\mathrm{m}}$ are the voltage magnitude values as $\delta_{\mathrm{k}}$ and $\delta_{\mathrm{m}}$ are the voltage phase angle values at the end buses $\mathrm{k}$ and $\mathrm{m}$ of the $\mathrm{i}^{\text {th }}$ line, respectively $[20]$.

In order to optimize the system, variable shunt devices are installed by the minimum number and size of Var instead of using fixed shunt capacitors. At the end of the process the active power loss is optimized by installing $2 \mathrm{SVC}$ devices in bus 15 and 21 with 13.74 MVAR total 
reactive power size. It is shown that the proposed algorithm converges better results when compared to the methods given by literature in Table 2 .

Table 1. Optimal settings of control variables for different cases.

\begin{tabular}{|l|c|c|c|}
\hline & Case 1 & Case 2 & Case 3 \\
\hline$V_{1}$ & 1.100 & 0.9954 & 0.9500 \\
\hline$V_{2}$ & 1.0976 & 0.9818 & 0.9770 \\
\hline$V_{5}$ & 1.0799 & 1.0187 & 1.1000 \\
\hline$V_{8}$ & 1.0867 & 1.0207 & 1.1000 \\
\hline$V_{11}$ & 1.0560 & 0.9693 & 0.9500 \\
\hline$V_{13}$ & 1.0209 & 1.0500 & 0.9500 \\
\hline$T_{11}$ & 1.1000 & 0.9791 & 1.1000 \\
\hline$T_{12}$ & 1.0414 & 0.9000 & 1.1000 \\
\hline$T_{15}$ & 0.9527 & 1.0555 & 0.0673 \\
\hline$T_{36}$ & 1.0367 & 0.9527 & 0.9000 \\
\hline$Q_{15 \text {-FACTS }}$ & $11.21(\mathrm{SVC})$ & - & - \\
\hline$Q_{19-\text {-FACTS }}$ & - & $6.73(\mathrm{SVC})$ & $2.15(\mathrm{STATCOM})$ \\
\hline$Q_{20 \text {-FACTS }}$ & $2.53(\mathrm{SVC})$ & - & - \\
\hline$Q_{21 \text {-FACTS }}$ & - & - & $13.42(\mathrm{SVC})$ \\
\hline$Q_{24 \text {-FACTS }}$ & - & $3.42(\mathrm{STATCOM})$ & - \\
\hline$P_{\text {loss }}$ & $\mathbf{3 . 0 4 5}$ & 0.0681 & 0.6745 \\
\hline$V D$ & 0.5992 & $\mathbf{0 . 0 8 2 4}$ & 0.2787 \\
\hline$L_{\max }$ & 1.3210 & 0.8921 & $\mathbf{0 . 1 0 9 5}$ \\
\hline$\sum Q_{C}$ & $\mathbf{1 3 . 7 4}$ & $\mathbf{1 0 . 1 5}$ & $\mathbf{1 5 . 5 7}$ \\
\hline
\end{tabular}

Table 2. Comparison of power loss and var sizing for different methods.

\begin{tabular}{|c|c|c|}
\hline Methods & $\boldsymbol{P}_{\text {loss }}[\mathbf{M W}]$ & $\boldsymbol{Q}_{c}$ [MVAR] \\
\hline SARGA [21] & 5.1170 & NR \\
\hline PSO [22] & 4.6501 & NR \\
\hline CLPSO [22] & 4.5800 & 47.2970 \\
\hline DE [23] & 4.5550 & 39.8043 \\
\hline BBO [24] & 4.5511 & 41.7309 \\
\hline GSA [25] & 4.5143 & 10.2358 \\
\hline OGSA [26] & 4.4984 & 29.5600 \\
\hline ABC [27] & 3.1078 & 39 \\
\hline Proposed best location with ABC & $\mathbf{3 . 1 0 4 5}$ & $\mathbf{1 3 . 7 4}$ \\
\hline
\end{tabular}

\subsection{Case 2 - Voltage profile improvement}

In this paper, the optimal location and size of FACTS devices is set by observing minimum value of voltage deviation (VD). Voltage deviation is calculated given in (20) where $\mathrm{N}_{P Q}$ defines load bus number of the system.

$f_{2}=\sum_{i=1}^{N_{P Q}}\left|V_{i}-1\right|$

In order to optimize the voltage profile improvement, given by (20), variable shunt devices are installed by the minimum number and size of Var instead of using fixed shunt capacitors. The shunt devices are placed randomly by the proposed algorithm and results are compared in 
Table 3. The minimum voltage deviation is obtained by placing SVC and STATCOM on buses 19 and 24 respectively. The optimal result for voltage deviation 0.0824 is obtained by injecting 10.15 MVAR total reactive power. It is shown that the proposed algorithm converges better results when compared to the methods given by literature in Table 3 .

Table 3. Comparison of voltage deviation for different methods.

\begin{tabular}{|c|c|c|}
\hline Algorithms & $\boldsymbol{V D}$ & $\boldsymbol{Q}_{\boldsymbol{c}}$ [MVAR] \\
\hline DE [23] & 0.0911 & 33.3567 \\
\hline PSO [28] & 0.0891 & 35.61 \\
\hline GSA [25] & 0.0676 & 25.4733 \\
\hline OGSA [26] & 0.064 & 20.19 \\
\hline Proposed best location with ABC & 0.0824 & $\mathbf{1 0 . 1 5}$ \\
\hline
\end{tabular}

\subsection{Case 3 - Voltage stability enhancement}

Voltage stability index is used to estimate the voltage issues of power systems most accurately in order to move the system far from voltage collapse state. The stability index is calculated by the voltage values of a system with no load and voltage collapse conditions [29].

The bus types in transmission systems are divided in two groups which are the generator (PV and Slack) and load (PQ) buses. Also a power system can be expressed and modeled in the form through Kirchoff Law given by (21) where subscript L and G symbolize the load and generator bus, respectively.

$I_{\text {system }}=\left[\begin{array}{c}I_{L} \\ I_{G}\end{array}\right]=\left[\begin{array}{ll}Y_{L L} & Y_{L G} \\ Y_{G L} & Y_{G G}\end{array}\right]\left[\begin{array}{c}V_{L} \\ V_{G}\end{array}\right]$

Here, $Z_{L L}=Y_{L L}^{-1}, A=-Z_{L L} Y_{L G}$. For any load bus, though the equation (21), the voltage of the bus is known as:

$V_{o j}^{*}=-\sum_{k \epsilon G} A_{j k} V_{k}$

The voltage stability vector of the load bus $\mathrm{j}$ will be easily obtained as given by (23) while objective function used for this case is given by (24),

$L_{j}=\left|1+\frac{V_{o j}^{*}}{V_{j}^{*}}\right|$

$f_{3}=\max \left(L_{j}\right)$

In order to optimize the Voltage Stability Index variable shunt devices are installed by the minimum number and size of Var instead of using fixed shunt capacitors likewise.

The proposed algorithm converges to better results when compared to the methods given in Table 4. Minimum $\mathrm{L}_{\text {index }}$ value is obtained by placing SVC and STATCOM on buses 19 and 21 , respectively. The optimal result for the voltage stability index 0.1095 is obtained by 
injecting 15.55 MVAR total reactive power which is $10.9 \%$ better than the best result reported in literature.

Table 4. Comparison of $\mathrm{L}_{\max }$ for different methods.

\begin{tabular}{|c|c|c|}
\hline Algorithms & $\boldsymbol{L}_{\max }$ & $\boldsymbol{Q}_{c}$ [MVAR] \\
\hline GA [30] & 0.1807 & 19.00 \\
\hline DE [23] & 0.1246 & 34.90 \\
\hline GSA [25] & 0.1368 & 45.00 \\
\hline OGSA [26] & 0.1230 & $3.21^{\text {(infeasible) }}$ \\
\hline Proposed best location with ABC & $\mathbf{0 . 1 0 9 5}$ & $\mathbf{1 5 . 5 5}$ \\
\hline
\end{tabular}

\subsection{Case 4 - Overloading condition}

In this case, real power demands of all load buses are increased by $20 \%$ in order to verify the and show the efficiency of the optimal location solution method. With the purpose of achieving the optimal parameters for the active power loss, voltage deviation and voltage stability problem, 2 shunt devices are located optimally and the results given by Table 5 . At the end of the process the active power loss is optimized by installing SVC devices in bus 12 and 21 with 18.74 MVAR total reactive power size. Minimum voltage deviation is obtained by placing STATCOM and SVC devices on buses 19 and 24 respectively. The minimum $\mathrm{L}_{\text {index }}$ is obtained by placing STATCOM and SVC on buses 10 and 12 respectively. The optimal result for the voltage stability index 0.1352 is obtained by injecting 13.69 MVAR total reactive power. Table 6 includes the comparison of the located devices on normal and overloading operation conditions of the power system. It can be seen that the proposed method converged to a new optimal solution on location the FACTS devices depending on the system parameters for the overloading condition.

Table 5. Optimal settings of control variables for overloading conditions.

\begin{tabular}{|c|c|c|c|c|}
\hline Control variables & \multirow{2}{*}{ Initial } & \multicolumn{3}{|c|}{ Overloading Condition } \\
\cline { 3 - 5 } & 1.05 & Power Loss & Voltage deviation & L $_{\text {index }}$ \\
\hline$V_{1}$ & 1.04 & 1.093 & 0.996 & 0.950 \\
\hline$V_{2}$ & 1.01 & 1.069 & 1.018 & 1.100 \\
\hline$V_{5}$ & 1.01 & 1.077 & 1.020 & 1.065 \\
\hline$V_{8}$ & 1.05 & 1.072 & 1.024 & 1.100 \\
\hline$V_{11}$ & 1.05 & 0.900 & 0.921 & 0.9500 \\
\hline$V_{13}$ & 1.078 & 1.100 & 1.033 & 0.9500 \\
\hline$T_{11}$ & 1.069 & 1.028 & 0.935 & 1.100 \\
\hline$T_{12}$ & 1.032 & 1.100 & 0.900 & 1.100 \\
\hline$T_{15}$ & 1.068 & 1.020 & 1.006 & 1.100 \\
\hline$T_{36}$ & 0.0 & - & 0.947 & 0.900 \\
\hline$Q_{10 \mathrm{FACTS}}$ & - & $0.0454(\mathrm{SVC})$ & - & $0.0213(\mathrm{STATCOM})$ \\
\hline$Q_{12 \mathrm{FACTS}}$ & - & - & $0.051(\mathrm{STATCOM})$ & $0.1156(\mathrm{SVC})$ \\
\hline$Q_{19 \mathrm{FACTS}}$ & - & $0.1420(\mathrm{SVC})$ & - & - \\
\hline$Q_{21 \mathrm{FACTS}}$ & - & $0.1931(\mathrm{SVC})$ & - \\
\hline$Q_{24 \text {-FACTS }}$ & 0.0 & - & 6.742 & 9.644 \\
\hline$P_{\text {loss }}$ & 5.842 & $\mathbf{6 . 3 0 3}$ & $\mathbf{0 . 0 9 2 9}$ & 0.8776 \\
\hline$V_{D}$ & 1.160 & 0.6468 & 0.1648 & $\mathbf{0 . 1 3 5 2}$ \\
\hline$L_{\text {max }}$ & 0.214 & 0.1579 & 24.43 & 13.69 \\
\hline$\sum \mathrm{Q}_{\mathrm{C}}$ & 0.0 & 18.74 & & \\
\hline & & & & \\
\hline
\end{tabular}


Table 6. FACTS device locations for different operating conditions of the power system.

\begin{tabular}{|c|c|c|}
\hline Objective functions & $\begin{array}{c}\text { Base condition } \\
\text { (Bus number/Device types) }\end{array}$ & $\begin{array}{c}\text { Overloading Condition } \\
\text { (Bus number/Device types) }\end{array}$ \\
\hline$P_{\text {loss }}$ & {$[15-20 /$ SVC-SVC $]$} & {$[12-21 /$ SVC-SVC $]$} \\
\hline$V D$ & {$[19-24 /$ SVC-Statcom $]$} & {$[19-24 /$ Statcom-SVC $]$} \\
\hline$L_{\max }$ & {$[19-21 /$ Statcom-SVC $]$} & {$[10-12 /$ Statcom-SVC } \\
\hline
\end{tabular}

\subsection{Case 5 - Multi-objective optimization of voltage stability, power loss and voltage deviation}

The multi-objective optimization problem can now be defined using the weighted sum of $\mathrm{fl}$, $\mathrm{f} 2$ and $\mathrm{f} 3$ to create the objective function given in (25) where $\mathrm{F}$ is the multi-objective function. The multi objective weights are chosen equal; as $\mathrm{w}_{1}=\mathrm{w}_{2}=\mathrm{w}_{3}=1 / 3$.

$F=w_{1} f_{1}+w_{2} f_{2}+w_{3} f_{3}$

In this case three objectives, power loss; voltage deviation and voltage stability index are optimized simultaneously. Two optimization algorithms, Artificial Bee Colony and Differential Evolution, are used in order optimize the multi objective power system problem with placing minimum number of devices in necessary buses. The convergence of the algorithm is shown in Figure 6 and the system parameters are given by Table 7. It can be stated that $\mathrm{ABC}$ can converge in smaller number of iterations and optimize the system in better manner with minimum number of devices. The optimal locations in respect of iterations are listed in the Table 8 which depicts the Pareto-optimal set of Case 4.

Table 7. Best location sets of shunt var compensators for two algorithms.

\begin{tabular}{|c|c|c|}
\hline Control variables & ABC & DE \\
\hline$V_{1}$ & 0.9959 & 0.9980 \\
\hline$V_{2}$ & 1.0016 & 0.9850 \\
\hline$V_{5}$ & 1.0130 & 1.0132 \\
\hline$V_{8}$ & 1.0132 & 1.0204 \\
\hline$V_{11}$ & 1.0061 & 0.9940 \\
\hline$V_{13}$ & 1.0143 & 1.0195 \\
\hline$T_{11}$ & 1.0092 & 0.9989 \\
\hline$T_{12}$ & 1.0092 & 0.9890 \\
\hline$T_{15}$ & 0.9762 & 1.0004 \\
\hline$T_{36}$ & 0.9414 & 0.9471 \\
\hline$Q_{15-\mathrm{FACTS}}$ & - & $0.0462(\mathrm{STATCOM})$ \\
\hline$Q_{19-\mathrm{FACTS}}$ & $0.0517(\mathrm{SVC})$ & $0.0132(\mathrm{SVC})$ \\
\hline$Q_{22-\mathrm{FACTS}}$ & $0.1644(\mathrm{STATCOM})$ & $0.0925(\mathrm{SVC})$ \\
\hline$P_{\text {loss }}$ & 0.0398 & 0.0748 \\
\hline$V_{D}$ & 0.1034 & 0.0878 \\
\hline$L_{\max }$ & 0.1363 & 0.1354 \\
\hline & &
\end{tabular}




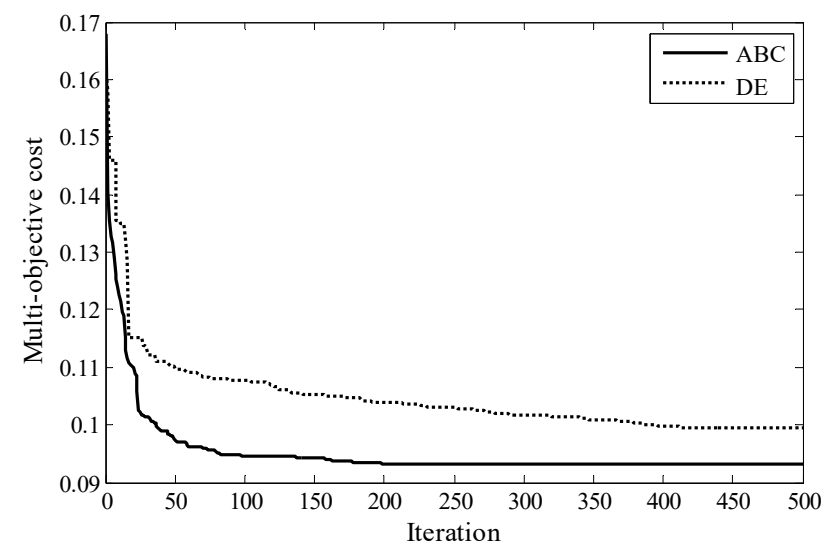

Figure 6. Convergence characteristics of different optimization methods for the optimal placement of shunt Var compensators

For the best optimal location control parameters of SVC and STATCOM devices are given by Figure 7. In figure optimal solution set for given system is evaluated by Newton-Raphson power flow method and $\mathrm{B}_{\mathrm{SVC}}$, $\mathrm{B}_{\mathrm{STATCOM}}$ variables are shown for respected iteration numbers. By evaluating the injected or absorbed reactive power value, Newton-Raphson algorithm applies the necessary reactive power to keep bus voltage values at a secure level decided by the user. Figure 8 shows the chosen 20 samples of the optimal locations decided by the algorithm during the optimization process of [f1; 2 ; f3]. The load bus number and device types of those 20 samples are given by Table 8 along with the pareto-optimal solution set for the overloading condition of the system.

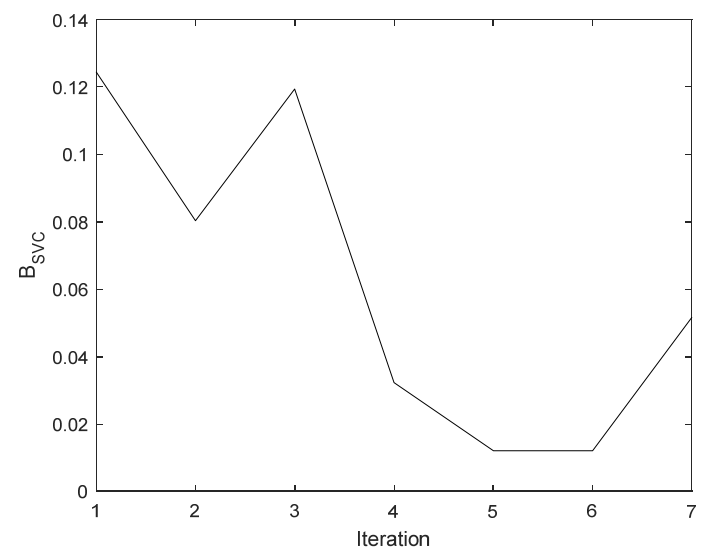

a)

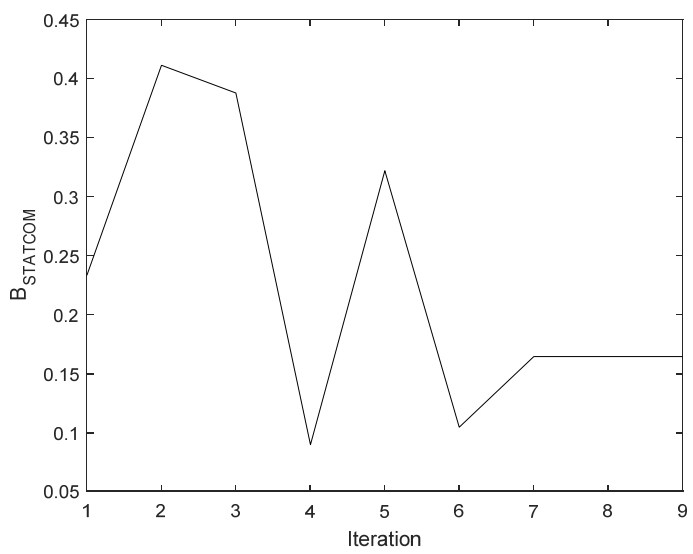

b)

Figure 7. $\mathrm{B}_{\mathrm{SVC}}$ and $\mathrm{B}_{\mathrm{STATCOM}}$ variables for optimal solution set.

The results show that the proposed algorithm locates FACTS devices randomly and converges to the best solution sets for each system by locating a SVC and a STATCOM on bus 19 and 22 for the normal system given by Case 4; a SVC and a Statcom on bus 19 and 24 for the overloaded system respectively. It is shown that the proposed algorithm converges better results when compared to the methods given by literature in Table 9 . 


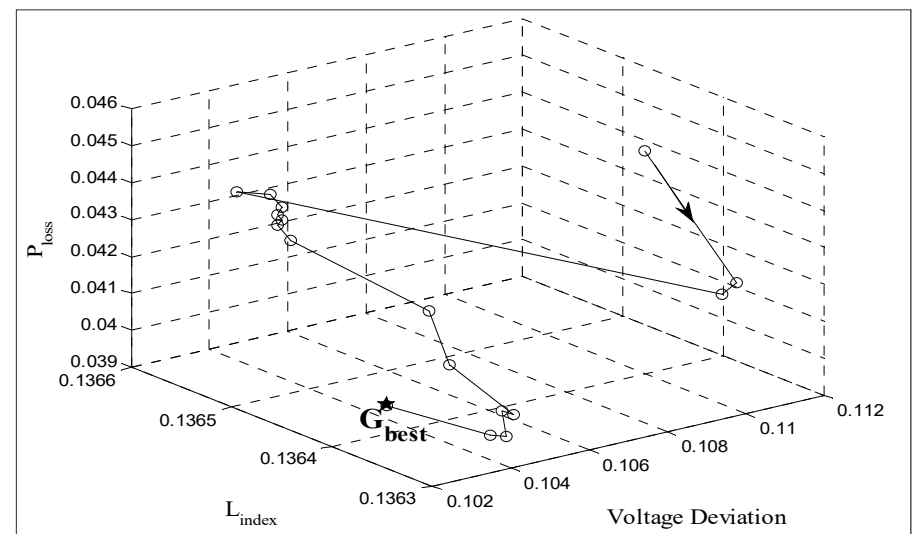

Figure 8. The Pareto solution set of ABC for case 5

Table 8. Pareto-optimal location solution set.

\begin{tabular}{|c|c|c|}
\hline Points & $\begin{array}{c}\text { Case 5 } \\
\text { (Bus number/Device types) }\end{array}$ & $\begin{array}{c}\text { Overloading Condition } \\
\text { (Bus number/Device types) }\end{array}$ \\
\hline Start & {$[17-21 /$ Statcom-Statcom $]$} & {$[10-12 /$ Statcom-Statcom $]$} \\
\hline 2 & {$[20-22 /$ SVC-Statcom $]$} & {$[19-22 /$ SVC-Statcom $]$} \\
\hline 3 & {$[18-21 /$ Statcom-SVC $]$} & {$[21-24 /$ Statcom-SVC $]$} \\
\hline 4 & {$[19-22 /$ SVC-Statcom $]$} & {$[19-24 /$ SVC-Statcom $]$} \\
\hline 5 & {$[19-22 /$ Statcom-Statcom $]$} & {$[19-22 /$ SVC-Statcom $]$} \\
\hline 6 & {$[19-22 /$ SVC-Statcom $]$} & {$[19-24 /$ SVC-SVC $]$} \\
\hline 7 & {$[19-22 /$ Statcom-SVC $]$} & {$[19-24 /$ SVC-SVC $]$} \\
\hline 8 & {$[19-22 /$ Statcom-SVC $]$} & {$[19-24 /$ SVC-Statcom $]$} \\
\hline 9 & {$[19-22 /$ SVC-Statcom $]$} & {$[19-24 /$ SVC-Statcom $]$} \\
\hline 10 & {$[19-22 /$ Statcom-Statcom $]$} & {$[19-24 /$ Statcom-Statcom $]$} \\
\hline 11 & {$[19-22 /$ Statcom-SVC $]$} & {$[19-24 /$ SVC-Statcom $]$} \\
\hline 12 & {$[19-22 /$ Statcom-Statcom $]$} & {$[19-24 /$ Statcom-Statcom $]$} \\
\hline 13 & {$[19-22 /$ Statcom-Statcom $]$} & {$[19-24 /$ Statcom-Statcom $]$} \\
\hline 14 & {$[19-22 /$ Statcom-SVC $]$} & {$[19-24 /$ SVC-Statcom $]$} \\
\hline 15 & {$[19-22 /$ Statcom-SVC $]$} & {$[19-24 /$ SVC-SVC $]$} \\
\hline 16 & {$[19-22 /$ Statcom-SVC $]$} & {$[19-24 /$ SVC-SVC $]$} \\
\hline 17 & {$[19-22 /$ SVC-SVC $]$} & {$[19-24 /$ SVC-SVC $]$} \\
\hline 18 & {$[19-22 /$ Statcom-Statcom $]$} & {$[19-24 /$ SVC-SVC $]$} \\
\hline 19 & {$[19-22 /$ SVC-Statcom $]$} & {$[19-24 /$ SVC-SVC $]$} \\
\hline $\mathrm{G}_{\text {best }}$ & {$[19-22 /$ SVC-Statcom $]$} & {$[19-24 /$ SVC-SVC $]$} \\
\hline
\end{tabular}

Table 9. Comparison of multi-objective functions different algorithms.

\begin{tabular}{|c|c|c|c|c|}
\hline & $\begin{array}{c}\text { Proposed } \\
\text { algorithm }\end{array}$ & $\begin{array}{c}\text { NSGA } \\
{[\mathbf{3 1}]}\end{array}$ & $\begin{array}{c}\text { MOEA/D } \\
{[\text { 31] }}\end{array}$ & $\begin{array}{c}\text { HMOPSO } \\
\text { [31] }\end{array}$ \\
\hline$P_{\text {loss }}$ & $\mathbf{3 . 9 8 0 0}$ & 5.2064 & 4.9803 & 4.8638 \\
\hline$V D$ & $\mathbf{0 . 1 0 3 4}$ & 0.1268 & 0.1137 & 0.1098 \\
\hline$L_{\max }$ & $\mathbf{0 . 1 3 6 3}$ & 0.1315 & 0.1301 & 0.1203 \\
\hline
\end{tabular}




\subsection{Case 6 - Optimal power flow of IEEE 57-bus power system in aspect of generation fuel cost minimization}

In this case, IEEE 57 bus power system is also solved and fuel cost function is optimized by using Artificial Bee Colony algorithm. Chosen test system consists of 7 generators, 3 shunt capacitors which injects reactive power to system and 13 load tap changer devices. By implementing the optimization algorithm with Newton-Raphson solver method, total fuel cost of the system is reduced and minimized while ensuring system security limits and constraints. Fuel cost function weights for generators are given by Table 10.

Table 10. IEEE 57-Bus fuel cost function weights for each generator.

\begin{tabular}{|c|c|c|c|}
\hline Generator & $\begin{array}{c}\mathbf{a} \\
\left(2^{\text {nd }} \text { order }\right)\end{array}$ & $\begin{array}{c}\mathbf{b} \\
\left(\mathbf{1}^{\text {st }} \text { order }\right)\end{array}$ & $\begin{array}{c}\mathbf{c} \\
(\text { constant })\end{array}$ \\
\hline$P_{1}$ & 0.077 & 20 & 0.00 \\
\hline$P_{2}$ & 0.010 & 40 & 0.00 \\
\hline$P_{3}$ & 0.250 & 20 & 0.00 \\
\hline$P_{4}$ & 0.010 & 40 & 0.00 \\
\hline$P_{5}$ & 0.022 & 20 & 0.00 \\
\hline$P_{6}$ & 0.010 & 40 & 0.00 \\
\hline$P_{7}$ & 0.032 & 20 & 0.00 \\
\hline
\end{tabular}

Total fuel cost convergence chart of the test system is given in Figure 9. As seen in the figure given below, optimization process is ended in 500 iterations where the best solution set and global minimum is obtained in iteration 181. Total fuel cost of the system is reduced to $4.161 \times 10^{4}$ from initial value of $4.424 \times 10^{4} \$ / \mathrm{h}$. Solution parameters of active power and generator voltages for the global minimum is given by Table 11 .

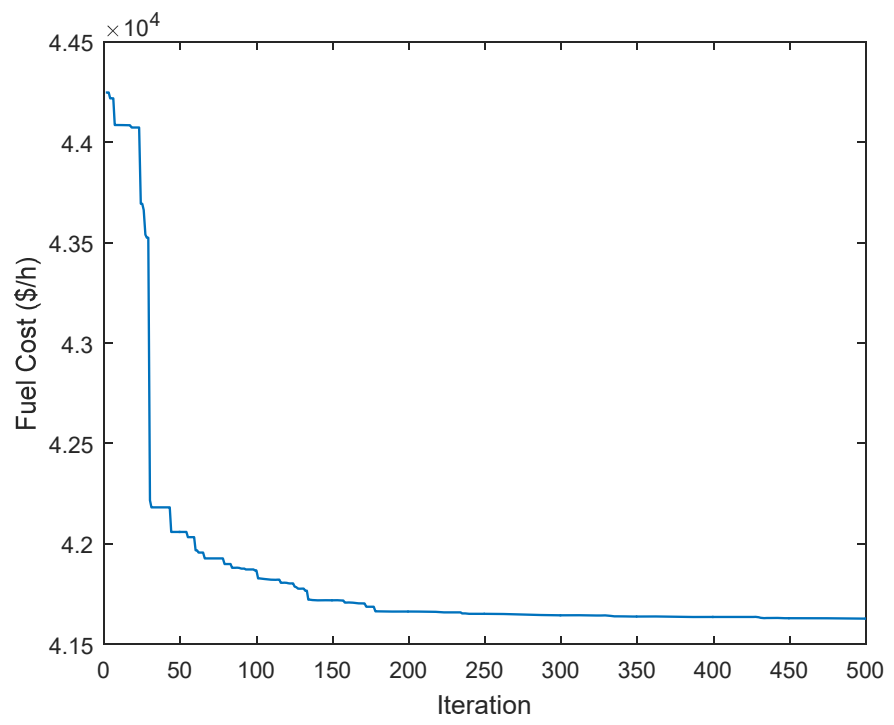

Figure 9. Cost function optimization chart of IEEE 57-Bus Test System 
Table 11. IEEE 57-Bus test system solution set for total fuel cost minimization.

\begin{tabular}{|c|c|c|c|c|c|c|c|}
\hline $\begin{array}{c}\text { Active Power } \\
(\mathbf{p u})\end{array}$ & $\mathbf{P}_{\mathbf{1}}$ & $\mathbf{P}_{\mathbf{2}}$ & $\mathbf{P}_{\mathbf{3}}$ & $\mathbf{P}_{\mathbf{4}}$ & $\mathbf{P}_{\mathbf{5}}$ & $\mathbf{P}_{\mathbf{6}}$ & $\mathbf{P}_{\mathbf{7}}$ \\
\cline { 2 - 8 } & 1.415 & 0.947 & 0.447 & 0.697 & 4.651 & 0.899 & 3.586 \\
\hline $\begin{array}{c}\text { Bus Voltage } \\
(\mathbf{p u})\end{array}$ & $\mathbf{V}_{\mathbf{1}}$ & $\mathbf{V}_{\mathbf{2}}$ & $\mathbf{V}_{\mathbf{3}}$ & $\mathbf{V}_{\mathbf{4}}$ & $\mathbf{V}_{\mathbf{5}}$ & $\mathbf{V}_{\mathbf{6}}$ & $\mathbf{V}_{\mathbf{7}}$ \\
\cline { 2 - 8 } & 1.086 & 1.084 & 1.098 & 1.071 & 1.100 & 1.029 & 1.068 \\
\hline
\end{tabular}

\section{Conclusions}

In this paper, a successful implementation of $\mathrm{ABC}$ algorithm is provided with novel methodologies applied for the optimal locations of SVC and STATCOM devices. Voltage stability enhancement and minimization of the real power loss and voltage deviation are considered as objective functions for the proposed methodology. Moreover, the best device location and types are decided by the proposed algorithm itself, where their optimum values are achieved for each objective functions. By using the minimum number of devices and injected reactive power values, better results of the objective functions are achieved than the state of the arts methods in literature. Furthermore, with the proposed method better results of the multi-objective function are achieved than the Differential Evaluation method.

\section{Acknowledgement}

This study is supported by Mersin University Scientific Research Project Council (Project code number: BAP-2018-1-TP3-2868).

\section{References}

[1] Mark Ndubuka Nwohu, "Voltage Stability Improvement using Static Var Compensator in Power Systems", Leonardo Journal of Sciences , 14, (2009): 167-172

[2] 1moh Moh M. Aung and Soe W. Naing, "Voltage Stability Improvement Using Static VAR Compensator With Fuzzy Logic Controller”, International Journal of Advanced Computational Engineering and Networking, , 4(8) (2016).

[3] Sarita S. Bhole , Prateek Nigam, "Improvement of Voltage Stability in Power System by Using SVC and STATCOM", International Journal of Advanced Research in Electrical, Electronics and Instrumentation Engineering, 4(2) (2015).

[4] S. Robak, M. Januszewski and D.D. Rasolomampionona, "Power system stability enhancement using PSS and UPFC Lyapunov-based controllers: A comparative study", Proc. of the Bologna Power Tech Conference Bologna, Italy, (2003): 23-26.

[5] D.A. Ingole and V.N.Gohokar, "Voltage Stability Improvement In Multi-bus System Using Static Synchronous Series Compensator Energy Procedia 117 (2017): 999-1006

[6] Romana Pradhan and Mohammed Nasir Ansari, "Voltage Stability Enhancement using Static VAR Compensator (FC-TCR).” , International Journal of Scientific \& Engineering Research, 6(2) (2015).

[7] C.S. Chang , J.S. Huang. "Optimal SVC placement for voltage stability reinforcement." Electric Power Systems Research 42 (1997): 165-172. 
[8] Tjing $\mathrm{T}$ Lie, Wanhong Deng. "Optimal Flexible AC Transmission Systems (FACTS)devices allocation.” Electrical Power \& Energy Systems, 19(2) (1997): 125134.

[9] S. Gerbex, R. Cherkaoui, A.J. Germond. "Optimal location of multi-type FACTS devices in power system by means of genetic algorithm." IEEE Trans. on Power Systems 16(3) (2001).

[10] Abacı K., Yamaçlı V., Akdağlı A. "Optimal power flow with SVC devices by using artificial bee colony algorithm." Turkish Journal Of Electrical Engineering \& Computer Sciences, DOI: 10.3906/elk-1305-55.

[11] M.M. Farsangi, H. Nezamabadi-Pour, K.Y. Lee "Multi-objective VAR planning with SVC for a large power system using PSO and GA." in: Proceeding of Power System Conference \& Exposition, (2006): 274-279.

[12] Benabid R., Boudour M., Abido M.A. "Optimal location and setting of SVC and TCSC devices using non-dominated sorting particle swarm optimization." Electric Power Systems Research 79 (2009): 1668-1677.

[13] Hsiao Y.T., Liu C.C., Chiang H.D. "A new approach for optimal VAR sources planning in large scale electric power systems.” IEEE Trans. Power Syst,8 (1993): 988-996.

[14] Kazemi A., Parizad A. , Baghaee H. "On the use of harmony search algorithm in optimal placement of FACTS devices to improve power system security." Proceedings of the IEEE Eurocon, Tehran, Iran, (2009): 570-576.

[15] Sirjani R., Mohamed A., Shareef H. "Optimal placement and sizing of Static Var Compensators in power systems using Improved Harmony Search Algorithm." Przegl ${ }^{1} \mathrm{~d}$ Elektrotechniczny, 87(7) (2011): 214-218.

[16] Acha E, Claudio R, Ambriz-Perez H, Angeles-Camacho C. "Facts modelling and simulation in power networks" New York: John Wiley and Sons, 2004.

[17] Erinmez, I.A., Foss, I., and I.C.o.l.h.V.E.systems, Static Synchronous compensator (STATCOM) : Cigre, 1999

[18] D. Karaboga, B. Akay. "A modified Artificial Bee Colony (ABC) algorithm for constrained optimization problems.” Applied Soft Computing, 11(3) (2011): 3021-3031.

[19] O. Alsac, B. Sttot. "Optimal load flow with steady state security." IEEE Transactions on Power Apparatus and Systems, 93 (1974): 745-751.

[20] Udgir S., Varshney S., Srivastava L. "Optimal Placement and Sizing of SVC for Voltage Security Enhancement.” International Journal of Computer Applications, 32(6) (2011).

[21] Subbaraj P, Rajnarayanan PN. "Optimal reactive power dispatch using self adaptive real coded genetic algorithm.” Electrical Power Systems, 79 (2009): 374-81.

[22] Mahadevan K, Kannan PS. "Comprehensive learning particle swarm optimization for reactive power dispatch.” Applied Soft Computing, 10 (2010): 641-52.

[23] Ela AAAE, Abido MA, Spea SR. "Differential evolution algorithm for optimal reactive power dispatch." Elec. Power Syst Res, (2011): 458-464

[24] Bhattacharya A, Chattopadhyay PK. "Solution of optimal reactive power flow using biogeography-based optimization.” Int J Electr Electron Eng, 4(8) (2010): 568-76.

[25] Duman S, Sönmez Y, Güvenc U, Yorukeren N. "Optimal reactive power dispatch using a gravitational search algorithm.” IET Gener Transm Distrib, 6(6) (2012): 563-76. 
[26] Shaw B. , Mukherjee V., Ghoshal S.P., "Solution of reactive power dispatch of power systems by an opposition-based gravitational search algorithm." International Journal of Electrical Power \& Energy Systems 55 (2014) 29-40.

[27] M. Rezaei Adaryani, A. Karami Artificial bee colony algorithm for solving multiobjective optimal power flow problem." Electrical Power and Energy Systems 53 (2013) 219-230.

[28] Abido M.A., "Optimal power flow using particle swarm optimization.” Int.j Electr. Power Energy Syst. 24(7):563-571.

[29] Kumaraswamy and P. Ramanareddy. Analysis of Voltage Stability using L-Index Method,(2011): 483-498.

[30] D. Devaraj, J. Preetha Roselyn. "Genetic algorithm based reactive power dispatch for voltage stability improvement.” Electrical Power and Energy Systems 32 (2010): 11511156.

[31] Yujiao Zeng and Yanguang Sun. "Application of hybrid MOPSO algorithm to optimal reactive power dispatch problem considering voltage stability." Journal of Electrical and Computer Engineering, Volume 2014, Article ID 124136. 